\title{
Laboreal
}

Volume $3 \mathrm{~N}^{\circ} 2$ | 2007

Trabalho infantil

\section{As implicações psicossociais do trabalho precoce de meninos e meninas em condição de rua}

Las implicaciones psicosociales del trabajo precoz de niños y ninãs en condición de calle

Les retombees psychosociales du travail precoce en condition de rue de jeunes garçons et filles

The psychosocial implications of premature work by street children

\section{Maria de Fátima Pereira Alberto}

\section{OpenEdition}

Journals

Edição electrónica

URL: http://journals.openedition.org/laboreal/12266

DOI: $10.4000 /$ laboreal. 12266

ISSN: 1646-5237

\section{Editora}

Universidade do Porto

\section{Refêrencia eletrónica}

Maria de Fátima Pereira Alberto, «As implicações psicossociais do trabalho precoce de meninos e meninas em condição de rua », Laboreal [Online], Volume $3 \mathrm{~N}^{\circ} 2$ | 2007, posto online no dia 01 dezembro 2007, consultado o 10 outubro 2019. URL : http://journals.openedition.org/laboreal/12266 DOI : 10.4000/laboreal.12266

Este documento foi criado de forma automática no dia 10 outubro 2019. 


\section{As implicações psicossociais do trabalho precoce de meninos e meninas em condição de rua}

Las implicaciones psicosociales del trabajo precoz de niños y ninãs en condición de calle

Les retombees psychosociales du travail precoce en condition de rue de jeunes garçons et filles

The psychosocial implications of premature work by street children

\section{Maria de Fátima Pereira Alberto}

\section{NOTA DO EDITOR}

Manuscrito recebido em : Março/2007

Aceite após peritagem em : Junho/2007

\section{Introdução}

1 Historicamente, o trabalho infantil existe desde a Antigüidade, mas com caráter diferente daquele que ele assume na sociedade contemporânea, capitalista, o caráter de explorador e predatório.

2 Nos países centros do capitalismo, o progresso tecnológico, a luta da classe operária e a mobilização da força de trabalho imigrante contra o trabalho infantil expulsaram ou reduziram a inserção das crianças no mundo do trabalho (Nogueira, 1993). Nos países de capitalismo periférico ou em desenvolvimento, o trabalho infantil continua sendo explorado: nos processos produtivos que envolvem relações de produção formal, para baratear a mão-de-obra adulta; e, no trabalho embutido, como complemento das empreitadas familiares. É também usado nas atividades informais. 
3 No Brasil, a existência do trabalho de crianças e adolescentes data da chegada das primeiras caravelas (Ramos, 2002), passando pelo período colonial, império e república. Após a abolição da escravatura, o trabalho infantil persiste. No campo, tinha por meta o processo de transmissão de habilidades de pais para filhos. Na cidade, aplicava-se, principalmente, às crianças, herdeiras da escravidão, na Casa dos Expostos e da Roda às crianças órfãs, abandonadas e desvalidas. Estas crianças tinham como prêmio e punição a criação de instituições asilares para cuidarem delas e de onde eram enviadas às oficinas públicas ou privadas, para as companhias de arsenais ou marinheiros.

4 No Brasil contemporâneo, o emprego da mão-de-obra infantil se dá também na economia informal, com estes tipos de atores : a) trabalhadores autônomos vendedores ambulantes, biscateiros, engraxates; b) prestadores de serviços olheiros de carro, lavadores de carro e vítimas da exploração sexual comercial ; c) ajudantes atuantes nas atividades exercidas pelo grupo familiar, nas empresas de fundos de quintais, vendedores ambulantes e barraqueiros, nos mercados públicos; d) trabalhadores domésticos; e) empregado nas atividades criminosas do narcotráfico e do crime organizado.

5 A temática trabalho infantil não é inédita. Vários autores, de diferentes orientações, já versaram sobre ela: investigaram o trabalho de crianças e adolescentes sobre os seguintes aspectos: a) crianças trabalhadoras no setor formal (Barros \& Mendonça, 1991; Alvim, 1979) ; b) no setor informal (Ferreira, 1979 ; Cervini \& Burger, 1991; Barros \& Mendonça, 1991); c) no setor urbano (Cervini \& Burger, 1991; Barros \& Mendonça, 1991) ; d) no setor rural (Antuniassi, 1981; Alessi \& Navarro, s.d ; Araújo, 1995 ; Moreira, 1995).

6 A maioria dos autores limitou-se aos efeitos decorrentes da não-escolaridade ou abordaram a relação entre trabalho infantil e saúde mental apenas a partir do que é visível, as condições de trabalho. Não investigaram o invisível, a organização do trabalho. Os pesquisadores que avaliaram a relação entre trabalho infantil e psiquismo (Sampaio \& Ruiz, 1996) não abordaram o setor informal de rua.

7 É neste contexto, do que se detectou como impreciso ou como carente de teorização, que se pretende apresentar algumas contribuições, mostrar as implicações psicossociais da inserção precoce no trabalho de meninos e meninas trabalhadores e trabalhadoras em condição de rua.

8 Esclareça-se que, ao referir-se a trabalho precoce, está-se considerando as atividades de trabalho desempenhadas por crianças ou adolescentes até os quatorze anos de idade - a mínima limite para ingresso no trabalho (na condição de aprendiz) e a máxima obrigatória para a escolaridade conforme determinam a Convenção 138 da Organização Internacional do Trabalho, a Constituição Federal do Brasil (Art. 227, parágrafo 3², inciso I) e o Estatuto da Criança e do Adolescente (Art. 60).

Por trabalho precoce, compreende-se o exercício da atividade socialmente útil ou esquemas de profissionalização divergentes, a exemplo do tráfico e da prostituição (Costa, 1985). Em outros termos, o que o trabalhador e a trabalhadora precoces fazem são atividades variadas, a cuja ação objetiva está inerente a intenção de obter pagamento, que pode ser em espécie ou em gênero.

10 Define-se meninos e meninas em condição de rua como : crianças e adolescentes, de ambos os sexos, que passam a maior parte dos dias nas ruas, desacompanhados, 
retirando, mediante o trabalho informal ou por atos ilícitos, o seu sustento ou o de suas famílias (Alberto, 1997).

\section{Aportes Teóricos}

11 Dado o tipo de objeto, seu caráter multifacetado, a dificuldade maior foi encontrar-se um referencial teórico-metodológico que pudesse dar conta da complexidade que envolve o trabalho precoce em suas dimensões sociais, psíquicas, econômicas e políticas. Delineou-se um quadro que apontou a necessidade de se trabalhar com a multidisciplinaridade, no sentido de compreender-se o mesmo objeto a partir de diversas óticas de análise, embora se tenha privilegiado a abordagem do trabalho precoce a partir de suas implicações psíquicas e sociais.

12 Na Psicossociologia, colheram-se subsídios para se analisar as implicações da inserção precoce no trabalho advindas das vivências subjetivas resultantes das interações entre o social (trabalho) e o psicológico, no sentido de constituição do sujeito (Dejours, 1986 ; Seligman-Silva, 1994b ; Blascovich \& Tomaka, 1991 ; Biaggio, 1996 ; Klein, 1979 ; Freitag, 1993 ; Carraher, 1989; Velho, 1985 ; Foucault, 1996). Entende-se que os processos subjetivos se constituem a partir de formas sociais concretas, construídas pelas ações dos indivíduos.

13 A Sociologia do Trabalho (Marx, 1987; Engels, 1977; Thompson, 1987) forneceu os elementos teóricos para análise das relações sociais de classe e de gênero e contribuiu para a compreensão das condições de vida e de trabalho.

Buscou-se apoio na Ergonomia (Daniellou, Laville \& Teiger, 1989 ; Wisner, 1987 ; Guérin et al., 1991) a fim de se poder realizar uma descrição objetiva das atividades de trabalho e compreender os fundamentos que as modelam, buscando alcançar o sentido e o significado das tarefas, visibilizando o trabalho precoce nas ruas.

Na Psicodinâmica do Trabalho (Dejours, 1986; Dejours, Abdoucheli \& Jayet, 1994), encontraram-se elementos de compreensão das vivências subjetivas de onde emergem os sofrimentos e as defesas. O sofrimento é concebido por Dejours et al. (1994) como a vivência subjetiva intermediária entre a doença mental descompensada e o conforto ou bem-estar psíquico. Embora os trabalhadores sofram, eles fazem uso de defesas para não adoecer. A especificidade da Psicodinâmica coloca em perspectiva e se apóia nas relações intersubjetivas do trabalho e nas vivências subjetivas de prazer e sofrimento no trabalho.

16 Toda essa complexidade é transversalizada pelas relações sociais de sexo (Hirata \& Kergoat, 1987). A presença de trabalhadores precoces nas ruas, no mercado informal, não é algo homogêneo; há singularidades decorrentes de ser menino ou menina. São nuanças que caracterizam a existência da divisão sexual do trabalho nas ruas.

17 O enfoque Psicossociológico é uma abordagem que pretende romper com a visão dicotômica indivíduo-sociedade, e se considera integrativa. Neste enfoque, impera a concepção do modo de os indivíduos e grupos perceberem e atuarem na sociedade e de serem influenciados pelas estruturas sociais.

Dentro do enfoque psicossocial, há diversas correntes, dentre as quais a cognição social, representações sociais, identidade social e subjetividade. Esta última será a adotada neste artigo, sendo mais especificamente a ênfase nos processos constitutivos de relações intersubjetivas, para se analisar as implicações psicossociais da inserção 
precoce no trabalho de meninos e meninas trabalhadores e trabalhadoras em condição de rua. relação Trabalho - Saúde Mental, mais especificamente os trabalhos de Seligman-Silva (1994b), que apresentam o conceito de desgaste como opção integradora do entendimento das capacidades mentais, cognitivas e psicoafetivas. $O$ desgaste referese :

(...) aos agravos psicossociais vinculados ao trabalho, (...) ou à expropriação da subjetividade em situações de trabalho onde a sujeição é intensa. 0 desgaste mental (...) não significa necessariamente doença. Significa essencialmente perda provisória ou definitiva de algo que antes fazia parte do trabalhador e do seu mundo mental (...) inclui desde desgastes literais orgânicos (...) até perdas de outra ordem como as perdas acarretadas para a identidade, para a densidade da própria vida afetiva ou para os projetos constituídos tendo em vista o futuro pessoal e da família (Seligmann-Silva, 1994a, p. 18).

Seligmann-Silva desenvolveu várias pesquisas com diversas categorias de trabalhadores, nas quais identifica inter-relações entre condições laborais e de vida e saúde. Dentre os resultados encontrados por ela, há dois que são particularmente 
importantes para : a interação entre espaço de trabalho e relação familiar e os efeitos deixados pelas experiências precoces de trabalho.

No primeiro caso, os resultados das pesquisas indicam uma forte correlação entre espaço laboral, relacionamento e cotidiano familiar. No segundo caso, os resultados indicam os efeitos deixados pela inserção precoce no mundo do trabalho: “(...) quem teve esse tipo de experiência inicial, uma conotação negativa às vezes se desenvolveu : o trabalho passou a significar violência e exploração" (Seligman-Silva, 1994b, p. 142).

É neste particular, nos aspectos psicossociais apontados pelas pesquisas, que se buscam subsídios. Conforme as contribuições que elas oferecem, principalmente no que tange à categoria desgaste, e que, neste artigo, se referem a categoria correlata, perdas, isto é, perdas da identidade, da dignidade, vida afetiva e expectativas de futuro, aspectos pertinentes ao desenvolvimento psicossocial dos sujeitos, objeto de nossa pesquisa.

\section{Método}

\subsection{Participantes}

A pesquisa foi realizada na cidade de João Pessoa, na capital do Estado da Paraíba['], com 26 crianças e adolescentes entre 07 e 14 anos de idade, trabalhadores nas atividades de vendedores, no sinal de trânsito e nas noites, vendedoras de quentinha, olheiros de carro e meninas em situação da exploração sexual comercial. O critério utilizado para a definição do tamanho da amostra foi o da saturação. De acordo com Sá (1998), no decorrer da pesquisa, se os temas começam a se repetir, isto significa que entrevistar uma maior quantidade de outros sujeitos pouco acrescentará de significativo ao conteúdo já apreendido.

\subsection{Instrumentos}

28 Usou-se a metodologia qualitativa e, como técnicas, quatro conjuntos de procedimentos: territorialização, observação sistemática, entrevistas semiestruturadas (individuais e coletivas) e histórias de vida.

\subsection{Procedimentos}

$\mathrm{Na}$ territorialização, começou-se a freqüentar os locais nas ruas onde os meninos e as meninas se concentravam, de modo que se pudesse demarcar e compreender os seus hábitos, o seu cotidiano e, ao mesmo tempo, a constância de sua presença. Assim uma personagem, até então estranha aos meninos e às meninas, passou aos poucos a ser percebida e fazer parte daquele cenário da rua, local geográfica e imaginariamente definido pelos meninos e pelas meninas como território que lhes pertence e do qual eles e elas se assenhorearam.

Feita a territorialização, com base no modelo de estudo do trabalho feito pela Ergonomia (Wisner, 1987), passou-se à observação e descrição das atividades de trabalho, das implicações, dos problemas de adaptação física e psíquica, contemplandose as condições que agem sobre o corpo e a organização do trabalho que age sobre a mente. 
31 As observações e descrições apontaram a necessidade de se esclarecer, junto aos meninos e meninas quanto ao modus operandi, além de alguns dados sobre a origem social e as vivências subjetivas. Foi feito por meio das entrevistas individuais semiestruturadas. Procuram-se elucidar as implicações do trabalho precoce, que foram expressos em palavras ou frases que revelaram o sofrimento e as perdas; concebidas neste artigo como categorias enunciativas das vivências subjetivas de meninos e meninas. São palavras ou expressões de sofrimento, de perda: desencorajamento, depressão, desmotivação, desânimo, agressividade, fontes de pressões, dificuldades, sentimento de vergonha e sentimento de inutilidade, medo e ansiedade. Além dos sofrimentos associados às exigências físicas das atividades, como dores e surgimento de doenças. Mas cumpre assinalar que a não-palavra, ou o silêncio, também foi considerado um elemento importante, revelador do sofrimento.

As entrevistas semi-estruturadas tinham um roteiro que contemplou os seguintes aspectos: identificação, condições de vida, ida para as ruas, condições de trabalho, inter-relações subjetivas nas ruas, exploração, sentido do trabalho, trabalho e família, trabalho e estudo, trabalho e perspectivas de futuro, relações sociais de sexo e divisão sexual do trabalho, trabalho e cansaço, imagens de si.

As observações e descrições foram gravadas e compuseram um relatório que foi devolvido, juntamente com a entrevista individual, aos meninos e meninas em grupo, para uma entrevista nos moldes de uma entrevista coletiva (Dejours et al., 1994). Procuram-se, nas entrevistas coletivas, detectar e enfatizar os comentários, objetos de discussão e de posições contraditórias, de consenso ou de fatores que marcavam as singularidades. Foram estes comentários, além dos silêncios, que constituíram material por excelência, nos relatórios de análise, das entrevistas coletivas.

O quarto procedimento utilizado foi a história de vida. Este recorte metodológico fez-se necessário tendo-se em vista à dificuldade de se fazer a observação sistemática com as meninas vítimas da exploração sexual comercial. Portanto este procedimento só foi usado com elas. $O$ porquê dessa dificuldade consistiu em alguns aspectos pertinentes à própria característica da atividade, do seu caráter privativo. 0 tipo de história de vida que utilizado foi aquele que enfatiza a história tópica que caracteriza determinada etapa da vida pessoal (Minayo, 1992, p. 126). Neste caso, enfatizou-se desde o momento que a menina foi inserida na exploração sexual comercial, destacando o dia-a-dia de trabalho, a hora em que começa a preparar-se, a firmar contrato com o cliente, até a transa propriamente dita e o retorno ao ponto.

Para análise dos dados, utilizamos a análise de conteúdo de Bardin (1977). Na análise qualitativa, a inferência é fundada na presença do índice, tema, palavra, personagem. Para efeito deste trabalho, a inferência está fundada na presença do tema. Os passos da interpretação estruturaram-se a partir dos seguintes aspectos: (a) organização dos dados, compreendendo a transcrição de fitas, leitura de material, organização de relatos e observações ; (b) categorização dos dados ; (c) análise final com as inferências e interpretações específicas aos instrumentos teóricos e metodológicos que nortearam o trabalho, relacionandose a especificidade do objeto, pela prova das vivências subjetivas, com as relações essenciais. 


\section{Resultados}

\subsection{Perfil}

São crianças e adolescentes que começaram a trabalhar em torno dos 06 e 10 anos e têm entre $01 \mathrm{e} 06$ anos de trabalho nas ruas. Todos têm uma defasagem escolar que varia de 1 a 7 anos. A maioria das famílias desses sujeitos originara-se de outras cidades. São provenientes do interior do Estado. O deslocamento deu-se pela necessidade de a família ou o próprio sujeito buscar trabalho, ou melhores possibilidades de trabalho na capital. As condições de vida são precárias, uma vez que, para a maioria dos sujeitos, as famílias enfrentam dificuldades - as mães criam a família sozinhas ou os pais encontram-se desempregados ou são biscateiros -, o que obriga os filhos a trabalharem precocemente.

\subsection{Organização das atividades}

37 Compreendeu-se, a partir dos dados, que há, nas ruas, um organizado sistema de comércio com a estruturação das atividades e das relações de trabalho. Os trabalhadores precoces em condição de rua são nômades. Todavia há os nômades circulantes e os nômades temporariamente fixos. Os primeiros são aqueles cuja característica da atividade requer constante movimento e que dependem deste movimento para executar as vendas. A parada só acontece para oferecer e negociar o produto. Os segundos, temporariamente fixos, são aqueles que ocupam um local fixo para a realização da atividade. $O$ deslocamento do referido local está condicionado a fatores externos e não à característica da atividade. Esses fatores externos podem ser, por exemplo, a ação do estado através dos órgãos de repressão. Há, nas ruas, a territorialização dos espaços urbanos. Cada território pertence a um grupo e é subdividido em pontos. Cada ponto é ocupado por um menino ou adulto. Essa divisão é feita por uma linha imaginária, já que não existe a demarcação visível do espaço. Esta divisão tem como critério a idade e o tempo no lugar.

38 A organização do trabalho e das relações de trabalho se dá sob a forma de um quadro de regras e condutas, elaboradas por quem vive no trabalho em condição de rua - crianças, adolescentes, jovens, adultos, autônomos, empregados e patrões. Os códigos são orais e referem-se ao que se pode ou não fazer. Os comportamentos proibidos são aqueles que podem desabonar o lugar aos olhos dos clientes ou que venham a desagradarlhes. Os que descumprem são chamados à atenção. Chama-se à atenção verbalmente. Mas já houve casos de expulsão. Também há hierarquia: há uma espécie de chefe da área, aquele que trabalha lá há mais tempo ou que se impôs pela força e que "manda" na área. Entretanto todos são autônomos nos seus respectivos pontos, na forma de trabalhar e nos ganhos.

Cinco aspectos são básicos no processo de trabalho: estruturação da atividade; inserção e aprendizagem; relações sociais de trabalho; exigências e competências; relações sociais de sexo com divisão sexual do trabalho.

1. Estruturação da atividade - Este aspecto compreende o processo de territorialização do local com a divisão por pontos de trabalho. O ponto é o lugar nas ruas onde se exercem as atividades. 
2. Inserção e aprendizagem - Este se refere à forma como o trabalhador precoce começa o processo de ocupação do seu ponto e a forma como aprendeu a desempenhar a atividade. A forma de inserção, por sua vez, inscreve-se num sistema de redes de solidariedade que estrutura as atividades de trabalho informais : amizade e parentesco.

3. As relações sociais de trabalho - Há os trabalhadores autônomos, que trabalham para si ou para a família, e os empregados que trabalham para um patrão a quem chamam " dono ». Aqui também há atividades cujo desempenho é feito por um só indivíduo, como também há aquelas que requerem coletivos de trabalho e divisão de tarefas.

4. Exigências e competências - Estes aspectos referem-se às prescrições, regras de disciplinamento do território, de convivência e qualificação para desempenhar as atividades.

5. Relações sociais de sexo com divisão sexual do trabalho - A inserção precoce se dá segundo uma construção social que hierarquiza os trabalhos entre meninos e meninas.

40 A maneira como esses aspectos, anteriormente descritos, funcionará na organização do trabalho precoce na informalidade diz respeito a cada atividade de trabalho. Esta organização do trabalho precoce estrutura a vida cotidiana, treina o corpo e a mente com tarefas esquematizadas, hábitos, horários de chegada e saída, horários das refeições e conteúdo das tarefas.

\subsection{As atividades de trabalho precoce}

\subsubsection{Vendedores no sinal}

41 São crianças e adolescentes que vendem frutas e legumes nos sinais de trânsito. Não há meninas nesta atividade. Estão expostos a situações de riscos : postura em pé o dia todo, exposição ao sol, à chuva, à poluição da fuligem dos carros ou da poeira do asfalto, os quais desprendem fragmentos de borracha. Há, ainda, os riscos inerentes aos caixotes pesados que eles carregam e que pesam entre $15 \mathrm{Kg}$ e $30 \mathrm{Kg}$. As distâncias do deslocamento variam, podendo ocorrer de os transportarem para uma distância de $100 \mathrm{~m}$ a 300m. São vulneráveis à violência, nas ruas, dos transeuntes que os tomam por marginais e os agridem verbalmente. Há, ainda, o perigo de atropelamentos. A atividade requer longas caminhadas cujo ritmo é ditado pelo sinal e pela quantidade de carros -, movimentos repetitivos do corpo e de levantamento de pesos. Há exposição aos esforços físicos e às posturas inadequadas ou incômodas. As exigências físicas aliam-se às exigências mentais decorrentes das condições e da organização do trabalho.

Há divisão de tarefas, que é feita por produtos, gênero, faixa etária, hierarquia. Cada um dos meninos apresenta e vende um tipo de fruta. Há coletivos de trabalho, que funcionam para as atividades de descarregar o carro que traz os produtos, de ensacálos, carregar caixotes pesados de uma distância para outra e guardar os produtos que sobram no final do dia. Embora haja coletivos para o desempenho dessas tarefas, vender é uma atividade individual e competitiva o que gera conflitos entre os vendedores.

\subsubsection{Vendedores na noite}

São crianças e adolescentes que vendem balas, refrigerantes, cervejas, salgados e bijuterias, nas ruas, à noite. Estão expostos aos riscos de estarem nas ruas, à noite, desacompanhados. São vulneráveis a vários tipos de violências : perversas agressões 
físicas, assaltos, emboscadas, roubos, maus-tratos. São ainda vulneráveis à violência dos transeuntes que os tomam por marginais e os agridem verbalmente.

Alguns dormem nas ruas, de modo que estão expostos às intempéries do tempo e as várias formas de violência, como agressões físicas e atentados de incêndio enquanto dormem[ $\left.{ }^{2}\right]$. Também são vulneráveis às drogas, ao tráfico e à arbitrariedade de policiais, que também os vêem como marginais em potencial e, sob qualquer alegação, “ fazem a revista " para ver se têm cola de sapateiro, ou ameaçam de levá-los presos[3] sem flagrante e sem ordem judicial de autoridade competente.

51 A atividade de olheiro exige esforço físico e psíquico. Físico, pelas demandas de postura e movimento do corpo ; psíquico, pela exigência de um estado de atenção permanente, sempre à espreita dos carros. Para os lavarem, executam movimentos contorcionistas 
com todo o corpo, curvam a coluna, contorcem o corpo, fazem movimentos repetitivos com os membros superiores, ficam nas pontas dos pés e agacham-se repetidamente.

\subsubsection{Meninas em situação de exploração sexual comercial}

52 São crianças e adolescentes do sexo feminino cuja vida sexual, da maioria, começou com o abuso sexual sofrido no contexto do lar, dentro da família, dos próprios pais. Muitas começaram a desempenhar esta atividade ainda no seio da família, entregando o ganho para esses parentes. Com a continuidade, revoltaram-se, fugiram dessa violência, foram para as ruas. Têm vidas precárias, com alimentação e moradias inadequadas, uma vez que vivem, dormem, alimentam-se, tomam banho, e fazem todas as suas necessidades nas ruas.

O desempenho da atividade nas ruas começa com a exposição do corpo para os clientes, em locais denominados de pontos, onde são feitos os contatos. Feita a negociação, meninas e clientes deslocam-se para motéis, pousadas ou, até mesmo, para um lugar escuro da cidade, dependendo da condição financeira do cliente. Esse deslocamento pode ser a pé ou de carro.

54 A jornada é variável : elas não contam por horas trabalhadas, mas pelo número de clientes que atendem. Normalmente, as "saídas" ou "programas", denominações usadas por elas, se dão à noite. Entretanto, como vivem nas ruas, podem, a qualquer momento, ser solicitadas por um cliente, a que elas atendem prontamente. Isto significa que pode ocorrer de fazerem programas também durante o dia. Este dado demonstra que a vida, o dia-a-dia e o trabalho se misturam, ou melhor, o tempo de trabalho contamina o tempo de vida.

É uma atividade que, por sua essência, demanda exigências de esforço físico e psíquico. No caso em questão, o do corpo feminino. Além do mais, considerando-se ser, esse corpo feminino o de uma criança ou adolescente, as exigências são maiores e comportam uma carga incompatível com o seu desenvolvimento. São posturas de corpo demandadas pelos clientes que, por pagarem, ditam as posições, que são incômodas, segundo o relato das meninas, e que causam dores.

Os riscos para a saúde das meninas decorrem da situação de rua, do desconhecimento do parceiro, da violência. Além das ameaças de morte, estão expostas às chuvas, às drogas, às doenças sexualmente transmissíveis, uma vez que, na maioria das vezes, não usam preservativos.

\subsection{A vivência danosa e as implicações psicossociais}

57 Acreditamos que a vivência da inserção precoce não passa incólume ao desenvolvimento desses meninos e meninas, deixando marcas em sua subjetividade. Observamos que são exatamente estas marcas que indicam o quanto a inserção precoce no mundo do trabalho, aliado ao local de trabalho, em condição de rua, é danosa e comprometedora para o desenvolvimento deles e delas.

Os dados empíricos fornecem-nos elementos que possibilitam a compreensão de que a inserção precoce, aliada à condição de rua, tem implicações psicossociais, é nefasta na vida dessas crianças e adolescentes. As implicações psicossociais aparecerão nos seguintes aspectos : imagem negativa de si e baixa auto-estima, adultização precoce, prejuízo à escolaridade, socialização desviante e incerteza nas expectativas de futuro. 


\subsection{Imagem de si e baixa auto-estima}

Auto-estima aqui está sendo compreendida como um componente auto-avaliativo do auto-conceito, ou seja, uma imagem de si carregada de valores. A auto-estima é a maneira como os indivíduos avaliam as suas características em relação àquelas dos seus semelhantes - o que implica, neste processo, a influência das interações sociais, a expectativa e a impressão causadas nos outros (Blascovich \& Tomaka, 1991).

A percepção da posse de um conjunto de competências contribui para um sentimento de auto-estima positiva. Os indivíduos experimentam sentimentos negativos por estes não corresponderem às expectativas sociais. Aqui há um paradoxo : a imagem que têm de si é de um trabalhador; logo uma imagem positiva. Mas os meninos e as meninas percebem que o seu trabalho não tem importância, não tem reconhecimento nem utilidade. Percebem-se, ainda, como marginais, vulgares, sem possibilidades de galgar um futuro melhor. Assim, compreende-se que têm uma imagem negativa de si e apresentam uma baixa auto-estima. Os meninos e as meninas vendedores têm uma imagem de si como trabalhadores e trabalhadoras. Reivindicam, por isso, uma identidade e tentam passá-la para os outros. Os outros compreendem os transeuntes, os agentes sociais do Estado, os clientes e os patrões para quem trabalham e que nem sempre, segundo eles, os vêem como trabalhadores. Apesar de se identificarem como trabalhadores, esses meninos e meninas apresentam baixa auto-estima por não serem tratados como trabalhadores e trabalhadoras.

Os meninos e as meninas trabalhadores precoces têm uma imagem de si como trabalhadores e trabalhadoras sem valor : acham-se sem importância, sofrem com isso, porque não vêem futuro no que fazem, e percebem seu trabalho como algo sem qualificação, que, por sua vez, não prepara nem qualifica para o exercício profissional futuro. Embora eles e elas elaborem uma imagem de si como de alguém sem valor, de menor importância, os vendedores e as vendedoras acham que podem encontrar, no aprendizado do lidar com o comércio e com as vendas, a qualificação que almejam. Já os olheiros não têm esta percepção quanto à atividade que desempenham nem quanto à continuidade ; pelo contrário : para eles, o que fazem poderá resultar em precarização de suas vidas para sempre. Enquanto as meninas em situação de exploração introjetam a estigmatização da sociedade de que são vulgares e " sem futuro » e sofrem com isso.

A pesquisa empírica mostrou que um outro núcleo aglutinador da auto-estima é marcado pelas relações sociais de sexo e pela divisão sexual do trabalho. Trata-se do sentimento de estigmatização, percebido ao longo das entrevistas dos meninos e das meninas. Não obstante, há uma diferença: enquanto elas se sentem estigmatizadas como vulgares, eles se sentem como marginais. Eles percebem-se como estigmatizados pela representação que, segundo seus depoimentos, a sociedade faz deles. Mas eles tentam afirmar-se pela negação dessa estigmatização, embora sintam isso como um peso, um estigma que carregam. Meninos e meninas falam de si como pessoas sem grandes possibilidades, que, sem alternativas profissionais, fazem dessas atividades estratégias de sobrevivência. Embora todos que vivenciam esta situação expressem o desejo de melhorar - o que significa obter um outro tipo de trabalho.

3 Conforme a abordagem analítica kleiniana, a imagem de si é constituída inicialmente a partir da imagem do corpo. No decorrer do desenvolvimento, junta-se a outros aspectos psíquicos, como estima de si. A imagem de si foi estudada por Melaine Klein (1979), na 
Psicanálise da Infância, cujos trabalhos elaboraram a concepção de que essa imagem começa a se formar a partir do corpo de outrem, da relação mãe-bebê, concebida por esta abordagem como o protótipo das relações sociais futuras. A imagem do corpo é culturalizada, socializada, de modo que é das relações interpessoais que emergirá a socialização. É nesses contextos relacionais que se desenvolverá a subjetividade. Da imagem de si emergirá, ou não, uma estima de si, como o amor próprio, influenciada pela maneira de imaginar-se como os outros os verão. A imagem de si depende da complacência dessas relações interpessoais, do aval social para consubstanciar-se, de modo que a imagem de si é um reflexo desse jogo de inter-relações. É desse jogo que emergirão os projetos de futuros pessoais e coletivos.

Esta imagem repercutirá no processo de elaboração de um projeto de vida, de futuro. Isto é, no processo de subjetivação com as mesmas características, uma baixa autoestima, sem amor próprio, sem valorização social, com sentimentos de inferioridade, sem aspirações, sem desejo. No caso das meninas, esta autodesvalorização é ainda mais complexa porque, além de elas se desvalorizarem como trabalhadoras e como indivíduos, há uma desvalorização quanto ao gênero. Segundo Hirata e Kergoat (1987, p. 06), "a desvalorização significa a negação de si, a personalidade é quebrada e a dor secretada". Isso tem conseqüências para a saúde psíquica, com a interiorização da opressão e da violência.

\subsection{Adultização precoce}

Os dados mostram que o trabalho precoce adultiza os sujeitos nele envolvidos, porque atribui responsabilidades e obrigações a crianças e adolescentes prematuramente. Estas responsabilidades prematuras têm conseqüências para a saúde, porque impedem o acesso desses sujeitos a vivências apropriadas e necessárias ao desenvolvimento, além de gerar um sentimento de sobrecarga, de perda, de pressão, de exploração, o que poderá levar, inclusive, ao desestímulo ao trabalho na vida adulta.

Constata-se que a adultização precoce é vivenciada pelos meninos e meninas como: pressão pela responsabilidade prematura no engajamento e na sobrevivência da família ; a inserção precoce no trabalho leva a adultização - o que gera sofrimento, pois impede a criança de realizar outros sonhos.

Segundo Seligmann-Silva (1994b), para quem teve a experiência do trabalho precoce, trabalho passa a significar violência e exploração. Além disso, do ponto de vista físico, a literatura pertinente dá conta de que a criança e o adolescente, por serem sujeitos em formação, têm organismos mais sensíveis aos elementos agressivos. Tarefas nocivas, como o carregamento de peso excessivo e postura inadequada, acarretam deformações corporais e debilidades físicas, interferindo na estrutura óssea, no peso e na altura. 0 trabalho acelera o envelhecimento do organismo (Silva-Filho et al., 1993).

Segundo teóricos do campo da Saúde Mental e Trabalho, altos níveis de responsabilidade geram relações interpessoais tensas e conflitivas. Portanto, com base nestes aportes e na utilização dos dados empíricos, entende-se que o trabalho precoce gera conflitos nos sujeitos por terem de agir como adultos quando, na realidade, não passam de crianças e adolescentes. 


\subsection{Prejuízos para a Escolaridade} que há prejuízo como a contaminação do tempo da escola com o tempo do trabalho. A necessidade prematura de trabalhar permeia o cotidiano de ambos os segmentos, de modo que esse tipo etário ocupa todo o seu tempo (a infância e adolescência) com as preocupações concernentes ao trabalho, contaminando, assim, o tempo que deveria ser dedicado aos estudos.

Dejours (1987), embora não trate da escolaridade, usa a expressão contaminação do tempo fora do trabalho para explicar que o homem é condicionado ao comportamento produtivo pela organização do trabalho. Deste modo, embora esteja fora do local de trabalho, o trabalhador conserva o mesmo corpo e a mesma cabeça. Ou mais especificamente : o trabalhador reproduz os estereótipos comportamentais, que são resíduos do tempo no trabalho. Entende-se que o trabalho interfere no processo de escolarização. Percebe-se que o trabalho precoce, no caso desses sujeitos contribui com o analfabetismo, promove o baixo nível de escolaridade e a defasagem escolar, porque dificulta o aprendizado da leitura e da escrita.

71 Todos apresentam uma defasagem escolar que varia de um a sete anos. Os que estudam freqüentam o ensino fundamental, da primeira à sexta série. Há diferenças decorrentes dos anos de escolaridade e tempo de trabalho. Percebe-se que os meninos apresentam maior tempo de escolaridade do que as meninas e maior número de desistências e evasão. Eles também começam a trabalhar mais cedo. Quem começou a trabalhar mais cedo, conseqüentemente, apresenta maior defasagem escolar e mais dificuldades para ler, escrever e usar uma linguagem mais estruturada conforme as regras gramaticais estabelecidas socialmente.

Observa-se que os meninos e as meninas apresentam dificuldades com a linguagem falada para exprimir seus pensamentos e idéias, assim como uma limitação do vocabulário. Esses dados parecem corroborar aqueles encontrados por Freitag (1993): as crianças escolarizadas tendem a expressar-se de forma mais socializada, enquanto crianças sem experiência escolar se expressam de modo mais preso aos padrões da fala egocêntrica. Carraher (1989), a propósito das dificuldades de crianças das classes populares com a linguagem falada, prefere conceber a existência de uma cultura do silêncio - própria do processo de colonização a que foram submetidas as classes populares ou, ainda, decorrente de um processo de negação do direito de acesso à alfabetização - a conceder a existência de um déficit lingüístico pertinente às crianças das classes populares. Entretanto, mesmo afastando-se a hipótese da existência de um déficit lingüístico, não se pode esquecer que essas crianças enfrentam na escola dificuldades desconhecidas pelas crianças das classes dominantes. A referida autora também enfatizou as desvantagens "que resultam do fato de que essas crianças utilizam uma variedade lingüística que diverge mais acentuadamente da língua escrita do que as crianças das classes dominantes" (idem, p. 104).

Hutz e Koller (1997) afirmam que os vários estímulos que a rua oferece exigem dos meninos e meninas de rua alerta e preparação constante para defenderem a integridade física e a sobrevivência - o que, segundo eles, deve gerar desequilíbrios cognitivos. Tais autores chegam, em seus trabalhos de campo, a conclusões que corroboram os dados aqui apresentados: “(...) observam que estas crianças e adolescentes apresentam dificuldade de prender a atenção em alguma tarefa mais 
específica por um período de tempo maior" (idem, p. 185). Disto se infere que a dificuldade de prender a atenção talvez seja um dos fatores que interferem na aprendizagem.

Os sujeitos queixam-se de que o trabalho cansa o corpo. A maioria deles estuda à noite, apesar de o cansaço já os ter consumido, o que dificulta a aprendizagem. Este dado leva a compreensão de que ele, assim, compromete o estudo porque leva esses meninos e meninas a não freqüentar a escola, o que acaba desestimulando e provocando a chamada evasão escolar.

Os dados corroboram os de Rizzini et al. (1996) de que as crianças e adolescentes que trabalham apresentam os maiores índices de evasão escolar. Cervini e Burger (1991) chegam a conclusões semelhantes, apenas diferenciando os percentuais para crianças e adolescentes. No caso das crianças, o índice de exclusão da escola é ligeiramente menor do que o dos adolescentes.

76 Segundo a Comissão Econômica para América Latina e o Caribe das Nações Unidas (CEPAL), as crianças e adolescentes trabalhadores, com idades compreendidas entre os treze e os dezessete anos, alcançam os dezoito anos com um déficit educativo de mais de dois anos escolares, em comparação com os jovens que ingressam no mercado de trabalho com idades compreendidas entre os dezoito e os vinte e quatro anos. Consideram, ainda, que este déficit educativo conduz a uma redução de $20 \%$ de ingresso na vida ativa quando são adultos (Oficina Internacional del Trabajo, 1996).

77 As concepções de Ferreira (1979), Bataglia (1993) e Nogueira (1993) corroboram os dados levantados porquanto demonstram que o trabalho precoce impede a escolarização e outras atividades formativas, por provocar a desistência e a evasão escolar. Bataglia (1993) diz que a evasão escolar constitui uma grave conseqüência do trabalho precoce, que dificulta a escolarização e a profissionalização. Nogueira (1993) afirma que Marx (1987) e Engels (1977), já no século XIX, chamavam a atenção para o fato de que a utilização que se fazia da mão-de-obra infantil colocava imensos obstáculos à instrução.

Os meninos e meninas sujeitos da nossa pesquisa referem-se à escola como um lugar inadequado para si ou que transmite conhecimentos que eles não entendem ou de que não gostam. São comportamentos que refletem a dificuldade de essas crianças e adolescentes se enquadrarem às exigências e ao tipo de socialização oferecida pela escola, e de a escola incorporar-se ou voltar-se para as experiências e realidades deles.

79 Conseqüentemente, predomina uma inabilidade da escola para lidar com os comportamentos de crianças e adolescentes que já são autônomos trabalhadores precoces que desenvolveram habilidades matemáticas na prática, no trabalho, mas que apresentam dificuldades em outras habilidades, como abstração de pensamento e pouca prática no uso da linguagem falada e escrita, principalmente para expressar o pensamento.

\subsection{Socialização desviante}

80 Socialização desviante significa que este aspecto do desenvolvimento não se dá na família, na escola, por meio de agentes socializadores considerados ideais pela sociedade. Isto significa que os comportamentos que os meninos e meninas adquirem são diferentes daqueles da média das crianças e adolescentes ou dos comportamentos 
médios que expressam uma harmonia com as exigências do funcionamento do sistema social (Velho, 1985).

81 No nosso entendimento, não é o trabalho por si só, mas, principalmente, o trabalho em condição de rua, de sujeitos em desenvolvimento, que promove o acesso a uma socialização desviante. Por socialização desviante entende-se o acesso ou o ingresso em atividades que conduzem à socialização com delitos e com atos infracionais. Tal processo desviante pode encaminhar meninos e meninas para a marginalidade. Também não é a rua que determina isto, mas ela o facilita pelos tipos de relações sociais que propicia, como o acesso às drogas, a exploração sexual comercial, a prática de pequenos delitos, o vício do jogo. Tanto os meninos como as meninas estão propensos a uma socialização desviante.

82 A influência do meio acontece, segundo eles, porque a necessidade do trabalho precoce os leva às ruas e, muitas vezes, as atividades de trabalho se constituem em esquemas de profissionalização divergentes. Assim sendo, a rua e o trabalho transformam-se em uma escola que ensina (ou facilita o acesso) a valores divergentes dos valores dominantes, considerados adequados para crianças e adolescentes.

\subsection{Incerteza nas expectativas de futuro}

83 O trabalhador e a trabalhadora precoces são sujeitos formados a partir de várias relações sociais e, como um mosaico que se perfila numa singularização, de trabalhadoras e trabalhadores sofridos, explorados, consumidos. O futuro é pensado como uma imagem negativa de trabalho. Os vendedores e vendedoras que trabalham para um patrão e os olheiros não sabem se terão um futuro melhor, mas desejam tê-lo. As meninas em situação de exploração sexual acreditam que não serão nada e que não terão futuro.

No caso das expectativas de futuro, a pesquisa empírica revela dois aspectos: uma expectativa de futuro que é da ordem do desejo, e outra que é da ordem da realidade. A primeira revela a aspiração a um futuro melhor, estudar (formar-se e ter um emprego regular que possibilite reconhecimento, dignidade e cidadania). Há uma outra expectativa de futuro na forma de desejo que se espelha em modelos heróicos : não estudaram, mas galgaram uma posição de destaque e adquiriram riqueza com o talento em alguma atividade artística ou esportiva. Os meninos, mais particularmente, alimentam desejos de conseguir futuro semelhante.

A segunda expectativa, da ordem da realidade, não se vê futuro a partir do trabalho atual. Esta é a expectativa da maioria dos meninos e das meninas. Para ambos os segmentos, o trabalho precoce representa uma atividade destrutiva. Para outros, as condições atuais de vida impossibilitam o projeto de família no futuro.

\section{Discussão}

Os aportes teóricos que utilizados conduzem à análise de que, no caso dos meninos e meninas em condição de rua, ocorre a produção de um sujeito mediante a efetivação de sua atividade, e, ao mesmo tempo, um esvaziamento desse sujeito que não consegue manter uma relação afirmativa com o que faz. Isto porque o trabalho precoce nas atividades informais nas ruas é precarizado e não é reconhecido socialmente, além de 
afetar-lhe para sempre o desenvolvimento, o que lhe custa caro para a vida toda. As defesas que criam, embora representem movimentos criativos em busca de saúde, não são suficientes para salvaguardar o desenvolvimento psicossocial. Há implicações psicossociais para o desenvolvimento.

É interessante ressaltar que o trabalho é instrumento de um jogo, que tem um duplo papel : ao mesmo tempo que é usado como modelador, é nefasto, causa sofrimento. $O$ trabalho precoce é explorado pelo capitalismo e usado pela sociedade como elemento disciplinador para as crianças das classes populares como opção para evitar o ingresso na marginalidade.

Formas mais sofisticadas de saber e poder - a disciplinarização e o panóptico (Foucault, 1996) não são mais as mesmas. O novo panóptico é a rua, lugar do trabalho informal. A disciplinarização não se exerce apenas com vistas a ser trabalhador, mas ser trabalhador e trabalhadora sem emprego, sem trabalho reconhecido socialmente, sem garantias sociais.

89 Seguindo essa linha de pensamento, entende-se que o trabalho continua formando a essência humana, não na práxis, no trabalho concreto, mas no não-trabalho, no nãodireito ao assalariamento com os direitos e garantias legais não assegurados pelo Estado (Castel, 1998; Antunes, 1997; Dowbor, 2000), que é sempre ausente, compactuando com as ilegalidades (Lautier, 1997 ; Cacciamali, 1999). Tudo isso significa uma essência que se forma nas práticas do "virar-se por si mesmo ", no " biscatear ", na inconstância do trabalho.

As mutações no capitalismo provocam a produção de novas subjetividades. As formas de trabalho que surgem de uma dessas mutações (como, por exemplo, as atividades informais) agenciam a produção de novas subjetividades, em que o trabalho precoce age como elemento disciplinador. Mas este é um trabalho que fragmenta a cidadania e a subjetividade, gera a exclusão social do acesso ao direito e à cidadania.

91 A subjetividade forma-se dentro de um processo complexo, no ser trabalhador sem trabalho fixo, no trabalho irregular, que caracteriza algumas formas de trabalho informal (como, por exemplo, atividades de trabalho informal executadas pelos meninos e meninas: vender frutas, doces, quentinhas, refrigerantes; olhar carro e situação de exploração sexual comercial). As meninas e os meninos se desenvolvem na forma de trabalho que joga crianças e adolescentes na solidão da vida, rouba e nega a sua infância (Martins, 1993), solapa seu poder de mãode-obra, impossibilita-os de serem trabalhadores com direitos sociais garantidos.

92 A carga das relações não é a divisão de tarefas. O acúmulo de carga psíquica se deu porque as atividades são percebidas pelos meninos e meninas trabalhadores como inúteis, desqualificadas, sujas, (Dejours, 1999; Dejours et al., 1994), sem futuro. Os meninos $\mathrm{e}$ as meninas sentem-se precocizados, explorados, marginalizados, estigmatizados e degradados. Há raras situações de gratificação; por isso eles “acumulam » um sentimento de frustração, de desgaste de quem perdeu algo (SeligmannSilva, 1994b), a própria infância. Sofrem com o sentimento de que o trabalho não os levará a lugar algum, de que não são bem vistos socialmente, pelo que fazem e por estarem em condição de rua.

o desgaste refere-se aos agravos psicossociais vinculados ao trabalho ou à expropriação da subjetividade em situações de trabalho. No caso dos sujeitos pesquisados, verifica-se a perda da infância, da capacidade de sonhar, das expectativas de futuro. $\mathrm{O}$ desgaste 
mental (...) não significa essencialmente perda - provisória ou definitiva - de algo que antes fazia parte do trabalhador e do seu mundo mental (...) inclui desde desgastes literais orgânicos (...) até perdas de outra ordem - como as perdas acarretadas para a identidade, para a densidade da própria vida afetiva ou para os projetos constituídos tendo em vista o futuro pessoal e o da família (SeligmannSilva, 1994b, p. 18).

Ao mesmo tempo, os meninos e as meninas não entendem o que aconteceu, porque têm uma imagem de si como trabalhadores. No entanto são estigmatizados, marginalizados e excluídos. Nem eles nem elas entendem como a vida os força à precocidade do trabalho, e a sociedade marginaliza-os, rechaça-os por isso. Não têm consciência, desconhecem a falsa ilusão de que se estão preparando, desde crianças, para serem trabalhadores, de que assim estão evitando cair na marginalidade. Mas sentem a rejeição desses outros e entendem que a atividade que fazem não propiciará uma qualificação para o exercício de uma atividade futura.

Apesar de os meninos e meninas reconhecerem o trabalho como perigoso, vulnerável à violência, gastador da infância, compreende-se que, para ambos os lados, identificar-se como trabalhadores pode ser ao mesmo tempo uma forma de vivenciar o prazer e uma ideologia defensiva para o enfrentamento dos aspectos enunciados anteriormente. Esta transformação do sofrimento em prazer ocorre porque o trabalho adquire sentido para quem o realiza, assim como, ocorre o reconhecimento simbólico (e material) de seu investimento afetivo e cognitivo no trabalho. Então, há um padecimento, um sofrimento neste tipo de trabalho e nesta condição de trabalhador, mas é também nela que se podem vivenciar as consideradas raras situações de prazer.

A noção de prazer defendida por Dejours (1987) não se ampara na teoria psicanalítica, não se refere à satisfação dos desejos inconscientes ligados às primeiras vivências de satisfação, mas, sim, à possibilidade de deslocamento da fonte de prazer. Esta fonte poderá ser encontrada, por exemplo, não apenas no conteúdo da atividade em si, mas também na busca de superação dos desafios provocados pela atividade. Compreende-se que, para os meninos e meninas, as raras situações de prazer se consubstanciam na capacidade que eles têm de superar as dificuldades e de recriar no trabalho nas ruas, estratégias de sobrevivência tanto no sentido de obter meios financeiros como no sentido de se defrontar com os perigos, os riscos, as humilhações, de superá-los e, sobretudo, de continuar vivos. Tal fato demonstra também um potencial de recriar a vida e regular as variações do organismo em busca da saúde. Mesmo que isto seja um paradoxo, pois nem sempre conseguem regular as variabilidades, a ponto de se constatarem sem futuro, com a vida gasta - o que é danoso para a saúde física e psíquica de crianças e adolescentes.

No caso do trabalho precoce dos meninos e meninas em condição de rua, pode-se dizer que alguns fatores, dentre outros, geram insatisfações e sentimentos de perda :

1. As atividades marginalizadas, desqualificadas.

2. A obrigatoriedade do trabalho precoce para sujeitos que precisam abrir mão de atividades apropriadas e necessárias às suas idades, como o brincar, o tempo livre e a escolaridade.

3. As atividades de trabalho precarizadas, em que se usa o corpo ou, mais especificamente, a sexualidade como estratégia de sobrevivência. Elas são percebidas como trabalho sujo.

4. As atividades de trabalho precarizadas não oferecem perspectivas de formação, tomam o tempo da escola e são percebidas pelos meninos e meninas como algo sem futuro e inúteis. 
98

Segundo dados do Centro de Referência em Saúde do Trabalhador - CEREST (Moura 1995), as inadequadas condições de trabalho geram nas crianças insatisfações pelo exercício de uma tarefa em que não há aprendizado técnico nem motivação secundária. As condições inadequadas podem, conseqüentemente, levar ao estresse emocional ou à fadiga psíquica. Ambas ocorrem quando há inter-relação entre contexto, vulnerabilidade e agentes agressivos. Por contexto, entende-se baixo padrão de vida, não-atendimento das necessidades básicas, segregação social e problemas de ajustamento familiar. A junção desses fatores faz com que muito cedo a criança perca a capacidade de sonhar, tenha uma baixa auto-estima em relação às suas capacidades intelectuais e produtivas - o que implica riscos para o seu desenvolvimento psicossocial, que serão determinantes para a perspectiva de futuro.

Trabalho pesado em idade precoce também tem outras conseqüências diretas no desenvolvimento físico e mental da criança. 0 corpo sofre os efeitos da fadiga, devido ao dispêndio excessivo de energia, mais do que o do adulto. $\mathrm{E}$ a maioria das crianças sofre também de má nutrição devido à ingestão de comidas inadequadas que baixam a resistência e as fazem ainda mais vulneráveis às doenças. A prevalência de anemia, de nutrição pobre e longas horas de trabalho facilitam a redução da capacidade de trabalho de crianças. A fadiga contribui para a frequiência de acidentes e enfermidades (Forastieri, 1997). força física e desgaste decorrentes do conteúdo das tarefas. Alimentam-se basicamente de carboidratos. Trabalham longas jornadas diurnas e noturnas (meninos vendedores no sinal, de dez a quatorze horas; meninos vendedores noturnos, de seis a oito horas; meninas vendedoras de quatro a oito horas). Embora não tenham sido medidas fadiga, resistência e doenças, eles e elas reclamaram de dores no corpo :

1. As meninas vendedoras queixam-se de dores na coluna e nas pernas por ficar sentadas durante a jornada de trabalho.

2. As meninas em situação de exploração sexual comercial queixam-se de dores no ventre e nas costas devido às posições exigidas pelos clientes e ao número de vezes que mantêm relações sexuais.

3. Os meninos vendedores no sinal queixam-se de dores nas costas, pernas, braços, mãos e dedos por passar o dia todo em pé e carregar caixotes pesados. Chegam até a cortar os dedos segurando os saquinhos de frutas.

4. Os meninos olheiros e lavadores de carro queixam-se de cansaço nas pernas, dor na coluna por carregar pesados baldes d'água ; queixam-se de dor na cabeça por passar o dia ao sol, por fazer contorções com o corpo para limpar os carros.

5. Os meninos vendedores na noite queixam-se de cansaço e dor nas pernas devido às longas caminhadas que fazem durante a jornada de trabalho e ao peso das mercadorias que carregam.

O sofrimento do corpo decorrente das dores tem implicações para o desenvolvimento. Não são apenas físicas, mas também psicossociais. Isto porque a tal sofrimento do corpo pode corresponder um estado de insatisfação e ansiedade. Esta última, inclusive, é de difícil explicação por eles próprios - difícil de traduzir em palavras. Segundo eles, sabem, mas não têm as palavras para dizer. Ambas, porém, poderão constituir-se em aspectos somatizados que repercutirão no desenvolvimento, podendo aparecer sob a forma de irritabilidade, agressividade, dificuldades de relacionamento, principalmente na escola. Podem aparecer, inclusive, no decorrer da vida, em relação à adaptação ao 
próprio trabalho, que é traduzido por alguns teóricos da saúde do trabalhador como desgaste (Seligmann-Silva, 1994a).

Outra conseqüência é para a escolaridade. Observa-se que os meninos e meninas usam gestos, expressão facial, movimentos do corpo, gírias, locuções ecolálicas (uma analogia a uma das formas de fala infantil de repetir o que o interlocutor usa) e outras vias de linguagem não formal. Logo o desenvolvimento intelectual e emocional poderá ser prejudicado. Intelectual porque, segundo Vygotsky (1989), (...) o pensamento nasce através da palavra. Uma palavra desprovida de pensamento é uma coisa morta, e um pensamento não expresso por palavras permanece uma sombra. (...) a palavra é o final do desenvolvimento, o coroamento da ação. Mas as palavras desempenham, além da comunicação social, elemento de inter-relação, papel na evolução histórica da consciência, cuja característica fundamental é uma reflexão da realidade (p. 131).

$\mathrm{O}$ acesso às expressões cognitivas e aos códigos formais se dá em função da classe social a que pertencem, como salienta Berstein (citado por Velho, 1997, p. 21): “(...) os desempenhos na aprendizagem variam em função de um prévio adestramento na utilização de uma linguagem verbal e de que as classes trabalhadoras revelam maiores dificuldades". Os sujeitos desta pesquisa têm consciência de que, se ficarem nestas atividades e se não estudarem, não terão perspectivas de futuro e ficarão fora de uma concepção valorizada de uma profissão que possibilite a cidadania e o bem-estar.

O trabalho precoce pesa no processo de subjetivação da criança em condição de rua. Afeta a formação de um universo simbólico da criança, porque a socialização, em vez de se dar na escola, se dá nas ruas, por outras vias. Isso os afetará, porque estarão precarizados, para o resto da vida, para empregos futuros que requererem instrução, conhecimento, capital cultural.

Um dos problemas é que essas crianças e adolescentes, ao serem obrigados a optar pelo trabalho nas ruas como instrumento socializador e afastar-se da escola, perderão a possibilidade de adquirir o capital cultural que é o fundamento para seu futuro, para seu desenvolvimento psicossocial, intelectual e de cidadania.

\section{Considerações finais}

106 As crianças e adolescentes em condição de rua são inseridas precocemente no trabalho devido a um conjunto de fatores: econômicos (necessidades de sobrevivência), psicossociais (conflitos familiares), culturais (um mercado que consome essa mão de obra), sócio-políticos (ausência de equipamentos institucionais de responsabilidade do Estado).

107 A inserção precoce desses meninos e meninas nas atividades informais segue uma divisão social e sexual do trabalho : para os meninos, as tarefas demandam o uso do corpo enquanto dispêndio de força física (carregar e segurar peso) ; para as meninas, as exigências são essencialmente do uso do corpo como objeto de propaganda ou de prazer para os clientes.

108 O trabalho de ambos os segmentos, vulneráveis à violência das ruas, implica riscos para a saúde. Mas há os riscos, decorrentes das atividades, que são diferentes para meninos e meninas : os meninos estão mais submetidos aos riscos provenientes de pegar peso e de postura, enquanto as meninas estão mais susceptíveis ao assédio sexual, ao constrangimento e às doenças sexualmente transmissíveis. 
Os dados empíricos mostraram que o sofrimento para os meninos e para as meninas é devido aos seguintes aspectos : dores no corpo; o olhar, a expressão e o tratamento do outro ; medo decorrente dos riscos devido às exigências de esforço físico e o desgaste provocado pelas tarefas e postura do corpo; as vivências subjetivas de sofrimento na inter-relação com o outro (transeuntes, clientes, patrões, agentes sociais, familiares e pares), dentre outros.

110 Os meninos e as meninas criam defesas coletivas e individuais: o silêncio, o riso, o gracejo, a zombaria, o choro, a vadiagem e as brigas na escola, o uso da virilidade, a minimização da realidade, a acomodação e o uso de drogas como formas de fuga. A inserção precoce, aliada à condição de rua, é nefasta à vida dessas crianças e adolescentes, e suas conseqüências se caracterizarão nos seguintes aspectos: uma imagem negativa de si e uma baixa auto-estima, a adultização precoce, a defasagem escolar, a socialização desviante e a falta de perspectivas de futuro.

Diante dessa realidade, mister se faz a adoção de medidas úteis com vistas à erradicação e prevenção do trabalho precoce :

1. Investir em programas de formação profissional e geração de renda para as famílias.

2. Criar e manter programas de ações sociais que atuem na prevenção ou na intervenção, junto às famílias, com demandas de atendimento psicossocial.

3. Prevenir, diagnosticar e acompanhar os agravos de saúde de crianças e adolescentes trabalhadores.

4. Organizar, através dos serviços de saúde, um sistema de informações e de notificação dos casos de trabalho precoce.

5. Incrementar ações de conscientização da família e de responsabilização dos pais por parte das entidades responsáveis pela defesa dos direitos da criança e do adolescente.

6. Implementar ações mais contundentes de fiscalização e penalização dos agenciadores e empregadores, por parte das entidades responsáveis pela fiscalização do trabalho e defesa dos direitos da criança e do adolescente.

7. Realizar campanhas de sensibilização da sociedade com vistas a desconstruir as práticas culturais que incentivam, oportunizam e consomem a mão de obra infantil.

8. Exigir do Estado o efetivo funcionamento da escola em tempo integral, de modo a torná-la inclusiva, integradora e de qualidade. 
Antuniassi, M. (1981). O trabalhador mirim na agricultura paulista. Tese de Doutoramento, Universidade de São Paulo, São Paulo.

Araújo, T. (Org) (1995). Os trabalhadores invisíveis crianças e adolescentes em situação de risco e pobreza, nos canaviais de Pernambuco. In Encontro Nacional da Associação Brasileira de Estudos do Trabalho (pp. 281-298). São Paulo : ABET.

Bardin, L. (1977). Análise de Conteúdo. (L. A. Reto \& A. Pinheiro, Trads.).

São Paulo : Edições 70/Martins Fontes.

Barros, R. \& Mendonça, R. (1991). As conseqüências da pobreza sobre a infância e a adolescência. In Fausto, A. \& Cervini, R. $O$ trabalho e a rua : crianças e adolescentes no Brasil urbano dos anos 80 (pp. 48-55). São Paulo : UNICEF/FLACSO/Cortez.

Bataglia, L. (1993). Meninos de rua : uma redução analítica da pobreza.

$2^{\mathrm{a}}$ ed. Rio de Janeiro : Ministério do Bem-Estar Social, CBIA, DIEST. Biaggio, A. (1996) Self e Moralidade. In Trindade, Z. \& Camino, C.

(Orgs.). Cognição Social e Juízo Moral. Rio Grande do Sul : ANPEPP. Blascovich, J. \& Tomaka, J. (1991). Measures of self-esteem. In Robinson,

J. P., Shaver, P. R. \& Wrightman, L. S. (Orgs.), Measures of personality and social psychological attitudes (pp. 115-160). New York: Academic Press

Brasil (1991). Ministério da Saúde. Ministério da Criança. Estatuto da criança e do adolescente, Lei 8.069/90. Brasília.

Brasil (1988). Constituição da República Federativa do Brasil. Brasília : Senado.

Cacciamali, M. (1999). Globalização, informalidade e mercado de trabalho. In Encontro Regional do Trabalho (pp. 369-388) João Pessoa : ABET.

Carraher, T. (1989). Sociedade e inteligência. São Paulo : Cortez.

Castel, R. (1998). As metamorfoses do trabalho. In Fiori, J. L. (Org.).

Globalização : o fato e o mito. Rio de Janeiro : EDUERJ.

Cervini, R. \& Burger, F. (1991) O menino trabalhador no Brasil urbano dos anos 80. In Fausto, A. \& Cervini, R. (Orgs.). O trabalho e a rua : crianças e adolescentes no Brasil urbano dos anos 80 (pp. 17-44) (2 ed.) São Paulo : Cortez.

Costa, A. (1985). A educação pelo trabalho. Revista Serviço Social e Sociedade, 19, (6), 13-25.

Daniellou, F., Laville, A., \& Teiger, C. (1989). Ficção e realidade do trabalho operário. Revista Brasileira de Saúde Ocupacional, 17, (68), 07-10.

Dejours, C., Abdoucheli, E., \& Jayet, C. (1994). Psicodinâmica do trabalho : contribuiç̃ões da Escola Dejouriana à análise da relação prazer, sofrimento e trabalho. São Paulo: Atlas.

Dejours, C. (1999). A banalização da injustiça social. Rio de Janeiro : Fundação Getúlio Vargas.

Dejours, C. (1987). A loucura no trabalho : estudo de psicopatologia do trabalho. São Paulo : Cortez-Oborê.

Dejours, C. (1986). Por um novo conceito de saúde. Revista Brasileira de Saúde Ocupacional, 14 (54), 7-11. 

Paulo : Martins Fontes. Labour Office. $5^{a}$ ed. São Paulo : Cortez. Paulo : HUCITEC. Paulo : DIFEL. Cortez. Paulo : Contexto.

Dowbor, L. (2000). Capitalismo : novas dinâmicas, outros conceitos. Retirado em Abril, 14, 2000, de http://www.ppbr.com/ld/capitalismo. shtml.

Engels, F. (1977). A situação da classe trabalhadora na Inglaterra. Lisboa : Presença ; São

Ferreira, R. (1979). Meninos de rua : valores e expectativas de menores marginalizados em São Paulo. São Paulo : CEDEC.

Forastieri, V. (1997). Children at work : health and safety risks. Geneva : International

Foucault, M. (1996). Vigiar e punir : nascimento da prisão. 14ª ed. Petropólis : Vozes.

Freitag, B. (1993). Sociedade e consciência : um estudo piagetiano na favela e na escola.

Guérin, F., Laville, A., Daniellou, F., Duraffourg, J. \& Kerguelen, A. (1991). Comprendre le travail pour le tranformer : le pratique de l'ergonomie. Paris : ANACT.

Hirata, H. \& Kergoat, D. (1987). Divisão sexual e Psicopatologia do Trabalho. In Encontro Anual da ANPOCS (pp. 01-14). Águas de São Pedro : ANPOCS.

Hutz, C. \& Koller, H. (1997). Questões sobre o desenvolvimento de crianças em situação de rua. Estudos de Psicologia, 2 (1), 175-197.

Klein, M. (1979). A Psicanálise das crianças. Rio de Janeiro : Imago.

Lautier, B. (1997). Os amores tumultuados entre o Estado e a economia informal. Contemporaneidade e Educação, 2 (1), 59-62.

Martins, J. (1993). Massacre dos inocentes : a criança sem infância no Brasil. $2^{\mathrm{a}}$ ed. São

Marx, K. (1987). Processo de trabalho e processo de valorização. In Marx, K. O Capital crítica da economia política. O processo de produção do capital. v. 1. t 1 (201-223). São

Minayo, M. (1992). O desafio do conhecimento: pesquisa qualitativa em saúde. São Paulo : HUCITEC ; Rio de Janeiro : ABRASCO.

Moreira, E., Kulesza, T. M. \& Leno, G. M. de L. (1995). Os caras-pintadas de suor e fuligem da cana. Relatório técnico de pesquisa. João Pessoa : UFPB/CNPq.

Moura, M. (1995). o trabalho precoce e a saúde de crianças e adolescentes. Oficina sobre os impactos do trabalho precoce na saúde de

crianças e adolescentes. Brasília, Mimeografado.

Nogueira, M. (1993). Educação, saber, produção em Marx e Engels. $2^{\mathrm{a}}$ ed. São Paulo :

Organização Internacional do Trabalho (1993). Convenção 138 e Recomendação no 146 sobre a idade mínima de admissão a emprego, 1973. Brasília : Gráfica Positiva.

Oficina Internacional del Trabajo. (1996). El trabajo infantil : ¿qué hacer? Documento Submetido a discusión de la Reunión Tripartita Oficiosa de Nivel Ministerial. Genebra : Oficina Internacional del Trabajo.

Ramos, F. (2002). A história trágico-marítima das crianças nas embarcações portuguesas do século XVI. In Del Priore, M. (Org.). História das crianças no Brasil. (pp. 19-54). São 
Rizzini, I. (Org) (1996). A criança e o adolescente no mundo do trabalho.

Rio de Janeiro : USU Ed. Universitária/Amais.

Sá, G. (1998). A construção do objeto de pesquisa em Representações Sociais. EDURJ : Rio de Janeiro.

Sampaio, I. \& Ruiz, E. (1996). Trabalho precoce e psiquismo infantil. São Paulo : Texto mimeografado.

Seligmann-Silva, E. (1994a). Aspectos psicossociais da saúde do trabalhador. Revista Travessia, 20 (3), 17-21.

Seligmann-Silva, E. (1994b). Desgaste mental no trabalho dominado.

Rio de Janeiro : UFRJ/Cortez.

Silva-Filho, J. (1993). Organização do trabalho e saúde mental: estudo das relações entre a prevalência de doenças mentais e organização do trabalho bancário no município do Rio de Janeiro. In Silva-Filho, J., Textos para discussão n.7. Rio de Janeiro : Fórum de Ciência e Cultura/Universidade Federal do Rio de Janeiro.

Thompson, E. (1987). A formação da classe operária inglesa : a maldição de Adão. $2^{\mathrm{a}}$ ed. Rio de Janeiro : Paz e Terra.

Velho, G. (1997). Individualismo e cultura. $4^{\mathrm{a}}$ ed. Rio de Janeiro : Jorge Zahar Editor.

Velho, G. (org.) (1985). Desvio e divergência : uma crítica da patologia social. $5^{a}$ ed. Rio de Janeiro : Jorge Zahar Editor.

Vygotsky, L. (1989). Pensamento e linguagem. $2^{a}$ ed. São Paulo : Martins Fontes.

Wisner, A. (1987). Por dentro do trabalho. Ergonomia : método \& técnica. São Paulo: FTD ; Oboré.

\section{NOTAS}

1. Este artigo é um fragmento de tese de Doutorado em Sociologia pela Universidade Federal de Pernambuco/Brasil (2002).

2. Eles revelaram que têm que sobreviver na rua em grupo ou, pelo menos, em dupla de modo que, à medida que um dorme, outro possa fazer a vigilância, pois são costumeiramente vítimas de tentativas de incêndio por parte de outras pessoas ou grupos que ateiam fogo aos papelões ou jornais que lhes servem como camas.

3. Vale salientar que, no Brasil, há uma Legislação específica. Trata-se do Estatuto da Criança e do Adolescente, segundo o qual, a prática de atos infracionais por criança implica o encaminhamento aos pais ou responsável mediante termo de responsabilidade. Quanto ao adolescente, só pode ser privado de liberdade mediante flagrante ou ordem escrita e fundamentada de autoridade judiciária competente. 


\section{RESUMOS}

Este artigo versa sobre o trabalho precoce em condição de rua nas atividades de vendedores no sinal de trânsito, vendedoras de quentinha, olheiros de carro e meninas em situação de exploração sexual comercial. Compreende-se que a inter-relação das condições de trabalho com a organização do trabalho tem implicações para a saúde física e mental. Utilizam-se como referências autores que abordam o campo da saúde mental, trabalho e subjetividade, particularmente a Psicossociologia, a Teoria do Desgaste, a Ergonomia e a Psicodinâmica do Trabalho. Usou-se a metodologia qualitativa e, como técnicas, quatro conjuntos de procedimentos : territorialização, observação sistemática, entrevistas (individuais e coletivas) e histórias de vida. Os resultados mostraram que a inserção precoce é nefasta na vida dessas crianças e adolescentes, com implicações psicossociais que aparecerão nos seguintes aspectos: imagem negativa de si e baixa auto-estima ; adultização precoce ; defasagem escolar ; socialização desviante e falta de perspectivas de futuro.

Este artículo trata del trabajo precoz en condición de calle en las actividades de vendedores en los semáforos, vendedoras de pensión, cuidantes y niñas en situación de explotación sexual mercantil. Se comprende que la interrelación de las condiciones de trabajo con su organización tiene implicaciones para la salud física y mental de estos niños. Se utilizan como referencias, autores del campo de la salud mental, trabajo y subjetividad, particularmente, la Psicosociología, la Teoría del Desgaste, la Ergonomía y la Psicodinámica del Trabajo. Se utilizó la metodología cualitativa $\mathrm{y}$, como técnicas, cuatro conjuntos de procedimientos: "territorialización " (conocimiento previo del sitio), observación sistemática, entrevistas (individuales y colectivas) e historias de vida. Los resultados muestran que la inserción laboral precoz es dañina para la vida de esos niños y adolescentes y tiene implicaciones tales como: imagen negativa de si, baja autoestima, madurez precoz, deficiencia escolar, socialización hacia prácticas ilícitas y falta de perspectivas de futuro.

Cet article traite de la condition précoce du travail dans les rues face aux activités des vendeurs qui restent aux feux rouges, des vendeuses de petits repas chauds, des garçons surveillants des voitures et des petites filles en situation d'exploitation sexuelle commerciale. On comprend que 1 'interrelation des conditions de travail et de l'organisation du travail a des conséquences pour la santé physique et mentale ; on utilise comme point de départ des auteurs qui travaillent dans le domaine de la santé mentale, du travail et de la subjectivité, en particulier la psychosociologie, la théorie de la perte, l'ergonomie et la psychodynamique du travail. Les résultats ont montré combien l'insertion précoce est néfaste pour ces enfants et adolescents et a des conséquences psychosociales qui présentent les aspects suivants: image négative et auto-estime très faible ; précocité dans l'apparence adulte; déphasage scolaire, socialisation déviante et manque de perspectives concernant l'avenir.

This article concerns the premature work, of street children, involved in the activities of hawking at traffic lights, food vendors, "carguardians" ; and girls in the situation of commercial sexual exploitation. It is understood that the interrelation of work conditions and work organization has implications for physical and mental health. We use, as reference, authors who study mental health, work and subjectivity, particularly psychosociology, impairment theory, ergonomics and work psychodynamics. Qualitative methodology is used and four sets of procedures are employed as technique : "territorialization", systematic observation, interviews (individual and group) and lifestories. The results showed that premature insertion is damaging to the lives of these children and adolescents, with psychosocial implications that are noticeable 
in the following aspects: negative image of themselves and low self-esteem; premature adulthood ; absence from school ; deviant socialization and a lack of prospects for the future.

\section{ÍNDICE}

Mots-clés: travail infantile, travail précoce, retombées psychosociales et santé

Palavras-chave: trabalho infantil, trabalho precoce, implicações psicossociais e saúde

Palabras claves: trabajo infantil, trabajo precoz, implicaciones psicosociales y salud

Keywords: child labour, premature work, psychosocial implications and health

\section{AUTOR}

\section{MARIA DE FÁTIMA PEREIRA ALBERTO}

Universidade Federal da Paraíba, R. Sebastião Interaminense, no 369 Edifício Porto Lugano Apartado 202, CEP 58.036-300 Bessa João Pessoa Paraíba - Brasil

jfalberto@uol.com.br 